This is the final peer-reviewed accepted manuscript of:

Z. Lei et al., Space charge characteristics of XLPE and semiconductive layer coated with graphene, in IEEE Transactions on Dielectrics and Electrical Insulation, vol. 27, no. 1, pp. 128-131, Feb. 2020

The final published version is available online at: https://doi.org/10.1109/TDEl.2019.008347

Rights / License:

The terms and conditions for the reuse of this version of the manuscript are specified in the publishing policy. For all terms of use and more information see the publisher's website.

This item was downloaded from IRIS Università di Bologna (https://cris.unibo.it/)

When citing, please refer to the published version. 


\title{
Space Charge Characteristics of XLPE and Semiconductive Layer Coated with Graphene

\author{
Zhipeng Lei ${ }^{1,2}$
}

1. Shanxi Key Laboratory of Mining Electrical Equipment and Intelligent Control, College of Electrical and Power

Engineering, Taiyuan University of Technology

Taiyuan, Shanxi 030024, China

\section{Davide Fabiani, Fabrizio Palmieri, Chuanyang Li, Tao Han, Giacomo Selleri, Filippo Grolli, Marco Speranza and Simone Vincenzo Suraci \\ 2. Department of Electrical, Electronic and Information Engineering 'G. Marconi', University of Bologna \\ Bologna 40136, Italy}

\begin{abstract}
Space charge can affect significantly the reliability of DC cross-linked polyethylene (XLPE) power cables. For limiting the injection and accumulation of space charge, specimens with graphene coating applied on a sandwich composed of XLPE and semiconductive layer were made. Space charge distribution of specimens was measured at 10 and $40 \mathrm{kV} / \mathrm{mm}$. The measuring results show that when graphene is coated on the semiconductive side, negative charge accumulates in XLPE, and the quantity of positive charge injected from anode is significantly reduced. When XLPE is coated with graphene, little space charge is injected into XLPE, and positive charge accumulates near the interface of XLPE and electrode, which lowers electric field near the anode.
\end{abstract}

Index Terms - graphene coating, space charge, XLPE, HVDC cable

\section{INTRODUCTION}

INJECTION and accumulation of space charge in DC crosslinked polyethylene (XLPE) power cable are one of the prime problems leading to the degradation and ageing of insulation [1, 2]. Many methods have been researched for blocking the injection of space charge into insulation. Milliere et al deposited a layer of silver nanoparticles embedded in a semiinsulating organosilicon matrix on the surface of polyethylene and found that space charge injection was suppressed by means of silver nanoparticles [3]. Du et al studied the space charge behavior of fluorinated polyimide. Their results showed that charge injection was suppressed through fluorination [4]. Moreover, $\mathrm{Li}$ et al investigated the influence of fluorination and $\mathrm{Cr}_{2} \mathrm{O}_{3}$ coating on creating surface traps affecting charge injection and provided a field-dependent charging model based on dominant charge transport behavior under different electric fields [5, 6].

Graphene is of unique physical properties. A layer graphene shows semimetal character with zero bandgap, which can be slightly increased up to $0.25 \mathrm{eV}$ in multi-layer graphene [7]. Therefore, the potential barrier height of junction where graphene is in contact with insulation is large and this may affect space charge injection. In order to block the charge

Manuscript received on 25 June 2019, in final form 9 July 2019, accepted xx July 2019. Corresponding author: D. Fabiani. injection into XLPE, this paper makes use of a graphene coating layer spread over the surfaces of the specimen. The space charge distribution in the insulation bulk was measured at different electric fields.

\section{EXPERIMENTAL SETUP}

\subsection{SPECIMEN PREPARATION}

XLPE specimens with a semiconductive layer (semicon) on one side for simulating the structure of cable system were made by Nexans. The thickness of XLPE insulation and semicon was about $400 \mu \mathrm{m}$ and $160 \mu \mathrm{m}$, respectively. For analyzing the effect of graphene coating on space charge, graphene dissolved in an appropriate solvent was mechanically applied by Nanesa S.r.l. on one side and both sides of XLPE and semicon. The main characteristics of the specimens are shown in Table 1. Then, all specimens were thermally treated under vacuum at $80{ }^{\circ} \mathrm{C}$ and 50 Pa for 24 hours in order to eliminate possible by-products and residual mechanical stress during preparation. The rationale behind this specimen configuration is to analyze the effect of graphene coating on charge injection from the electrodes and the possible interaction with the semicon. For this purpose, specimen B simulates a real cable situation, where graphene coating can be applied only outside the semicon and not directly in contact with the insulation. 
Table 1. Sheet resistance of specimens.

\begin{tabular}{c|cc}
\hline \multirow{2}{*}{ Name } & \multicolumn{3}{|c}{ Sheet resistance of graphene layer $(\Omega / \mathrm{sq})$} \\
\cline { 2 - 3 } & XLPE side & Semiconductive side \\
\hline specimen A & No graphene & No graphene \\
specimen B & No graphene & 3700 \\
specimen C & 5700 & 3000 \\
\hline
\end{tabular}

\subsection{MEASUREMENT SETUP}

The electrode configuration for different specimens is shown in Figure 1. The anode is made by semicon and the cathode is aluminum. During space charge measurement at room temperature, the applied electric field was $10 \mathrm{kV} / \mathrm{mm}$ and 40 $\mathrm{kV} / \mathrm{mm}$. The specimen was first polarized for about $10800 \mathrm{~s}$, and then depolarized for about $3600 \mathrm{~s}$. Before the measurement at each electric field, the specimens were short-circuited and discharged at $50{ }^{\circ} \mathrm{C}$ for $48 \mathrm{~h}$.
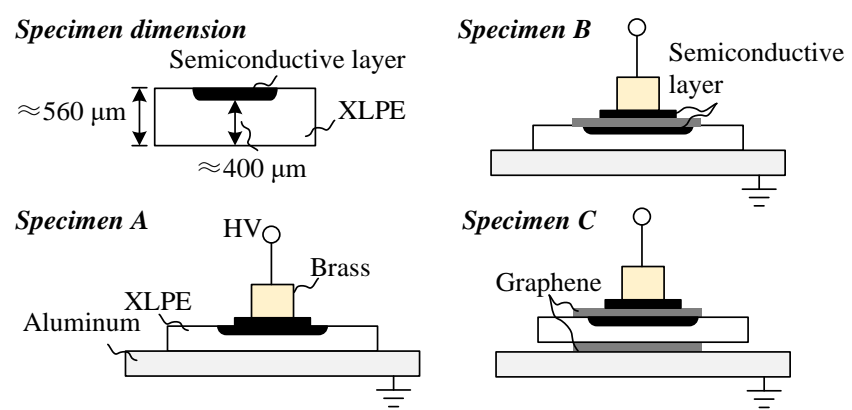

Figure 1. Specimen dimension and electrode configuration.

\section{RESULTS AND DISCUSSTION}

\subsection{SPACE CHARGE OF SPECIMEN A}

Figure 2 shows the space charge profiles of specimen without graphene coating at $10 \mathrm{kV} / \mathrm{mm}$. It can be seen from Figure $2 \mathrm{a}$ that the peak value of negative charge decreases and the peak of positive charge moves towards XLPE, which is believed the occurrence of charge injection. A small amount of homocharge is injected from both anode and cathode. Indeed, during the depolarization, the accumulation of homocharge in the vicinity of both anode and cathode can be seen in Figure 2b.

Figure 3 shows space charge profiles of specimen $A$ at 40 $\mathrm{kV} / \mathrm{mm}$. At the beginning of poling phase, a negative charge accumulation can be observed in the insulation bulk. Then, homocharge injected from anode increases and neutralizes the negative charge. However, it is difficult to differentiate whether negative charge can be due to the accumulation of ionic species coming from impurities or injection from cathode. During voltoff, homocharge injected from both electrodes can be observed. The charge density of homocharge is larger than that at 10 $\mathrm{kV} / \mathrm{mm}$. Figure $3 \mathrm{~b}$ shows that the negative charges may originate from the impurities in material, migrate from cathode to anode at the initial poling stage and charge is injected from anode. At the same time, negative charge is injected into XLPE from cathode accumulating as homocharge.

\subsection{SPACE CHARGE OF SPECIMEN B}

The space charge of specimen $B$, i.e. that with graphene coating outside the semicon side, at a poling field of $10 \mathrm{kV} / \mathrm{mm}$ is shown in Figure 4. It is noteworthy that space charge distribution of specimen B is similar to specimen A at 10 $\mathrm{kV} / \mathrm{mm}$. During poling phase, a small amount of homocharge is injected into XLPE at both electrodes and the peak value of the interfacial charge at two electrodes slightly decreases with time. The interfacial charge density of specimen $\mathrm{B}$ between semicon layer and XLPE is lower than that of specimen A. Although graphene coated on the surface of semicon side cannot totally prevent semicon layer from charge injection, homocharge accumulating close to the anode dissipates quite fast during depolarization.
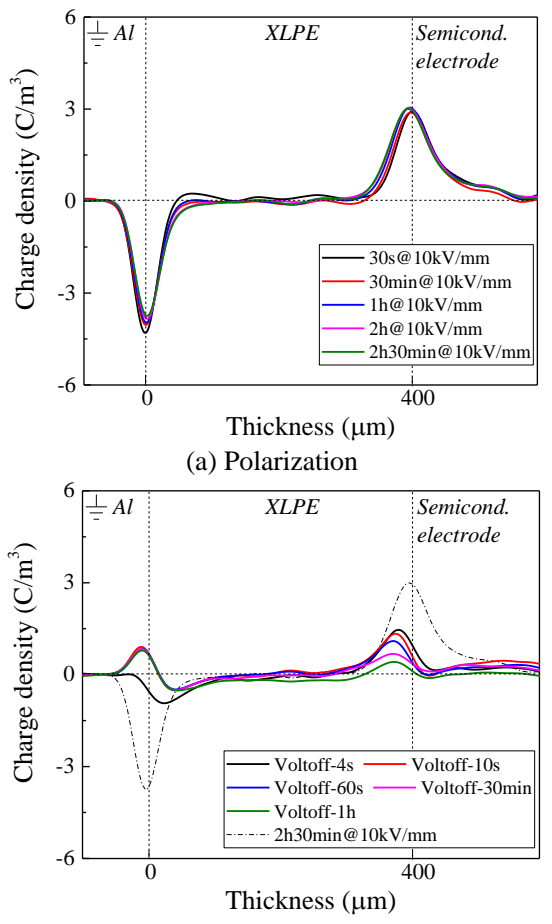

(b) Depolarization

Figure 2. Space charge profiles of specimen A at $10 \mathrm{kV} / \mathrm{mm}$.

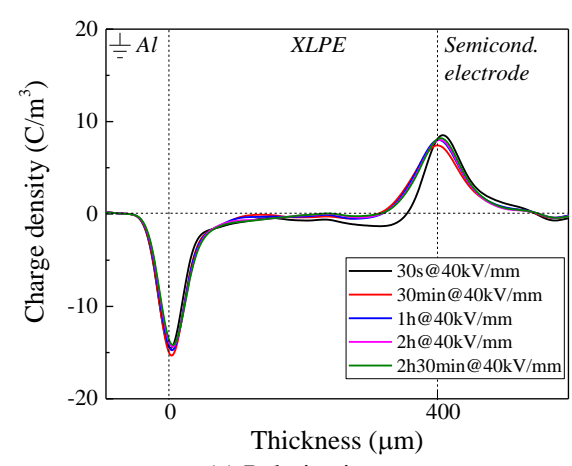

(a) Polarization

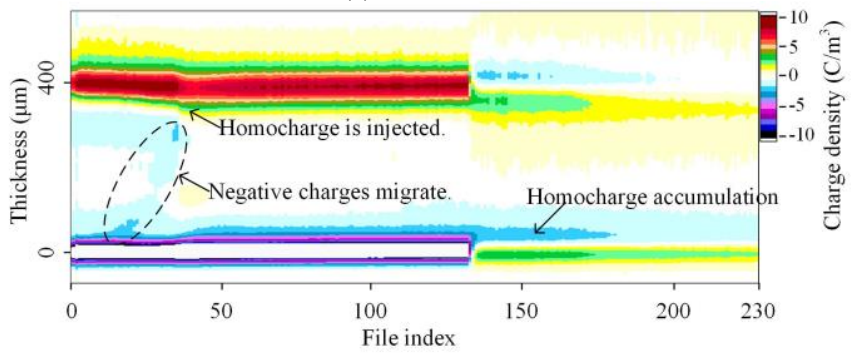

(b) Space charge distribution

Figure 3. Space charge profiles of specimen A at $40 \mathrm{kV} / \mathrm{mm}$. 


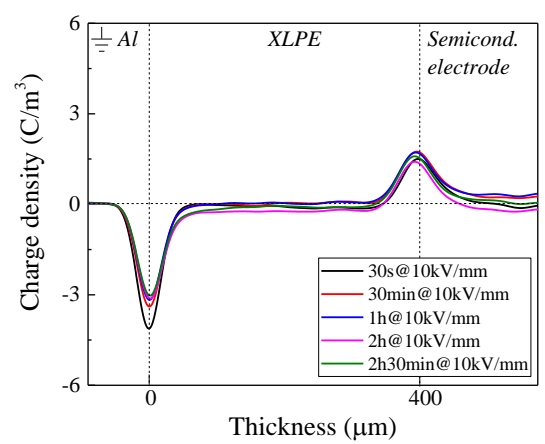

(a) Polarization

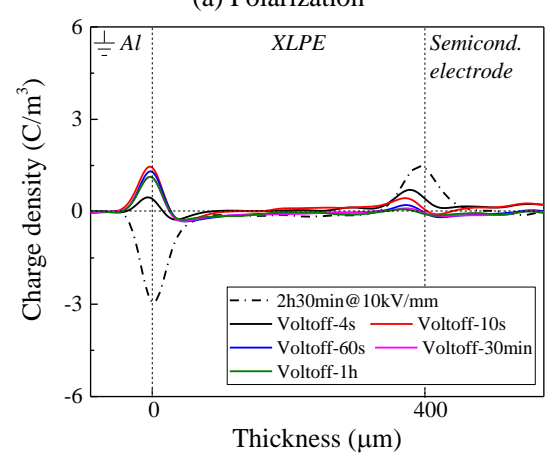

(b) Depolarization

Figure 4. Space charge profiles of specimen $B$ at $10 \mathrm{kV} / \mathrm{mm}$.

Figure 5 reports the space charge profiles of specimen B at 40 $\mathrm{kV} / \mathrm{mm}$. When the electric field rises to higher values, homocharge can be easily injected from cathode. Moreover, compared to specimen A, homocharge migrates from cathode to anode and accumulates in XLPE bulk, which leads positive charges originated from anode injection to decrease. From Figure $5 \mathrm{a}$ and $5 \mathrm{~b}$ it can be seen that both injection depth and the amount of negative charges injected from cathode at $40 \mathrm{kV} / \mathrm{mm}$ are larger than at $10 \mathrm{kV} / \mathrm{mm}$, which results in the increase of the electric field near the anode.

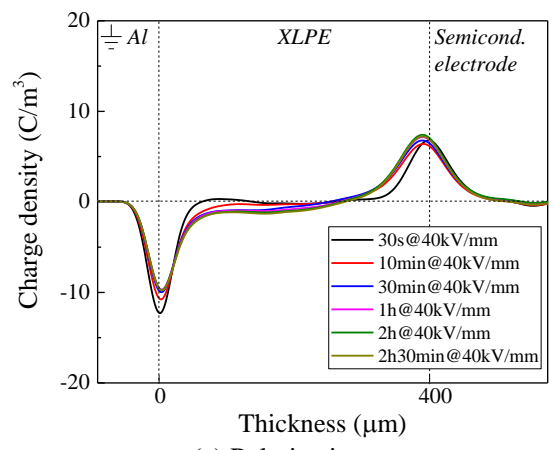

(a) Polarization

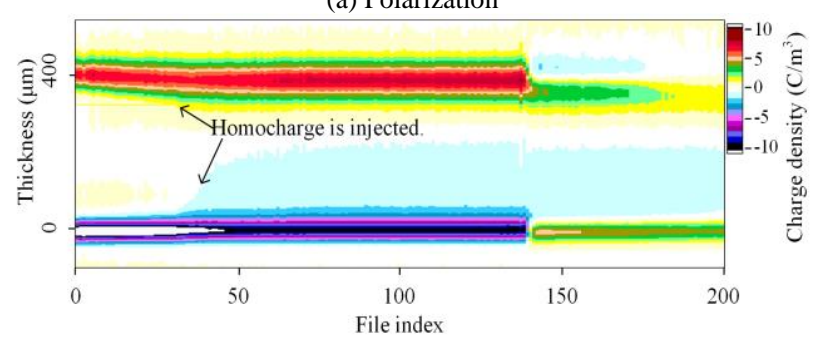

(b) Space charge distribution

Figure 5. Space charge profiles of specimen B at $40 \mathrm{kV} / \mathrm{mm}$.

\subsection{SPACE CHARGE OF SPECIMEN C}

Figure 6 shows the space charge profiles of specimen coated with graphene on both sides at $10 \mathrm{kV} / \mathrm{mm}$ and room temperature. It is worth noting that at this low electric field, the injection phenomenon is not evident.

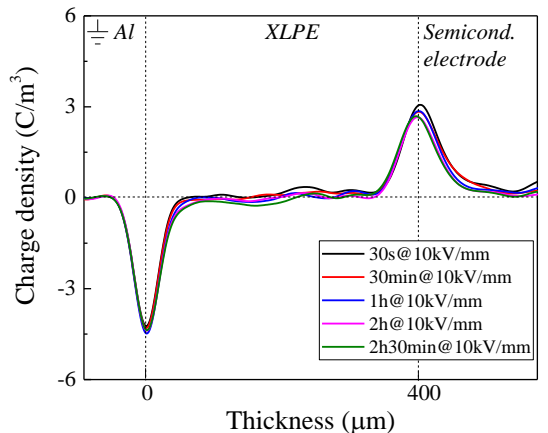

(a) Polarization

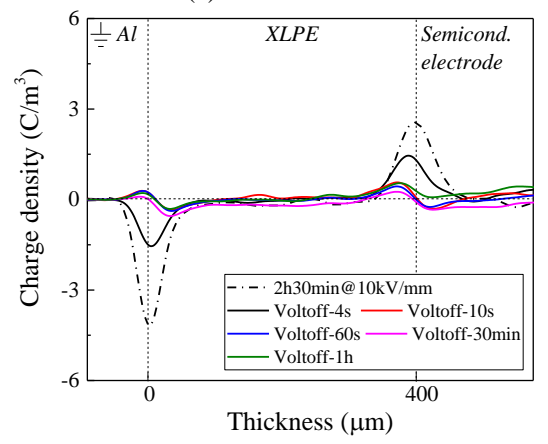

(b) Depolarization

Figure 6. Space charge profiles of specimen $\mathrm{C}$ at $10 \mathrm{kV} / \mathrm{mm}$.

When electric field rises to $40 \mathrm{kV} / \mathrm{mm}$ as shown in Figure $7 \mathrm{a}$, during poling phase, heterocharge at cathode accumulates with time, and no clear evidence of injection can be seen. However, homocharge accumulation close to the anode is well observable during depolarization phase.

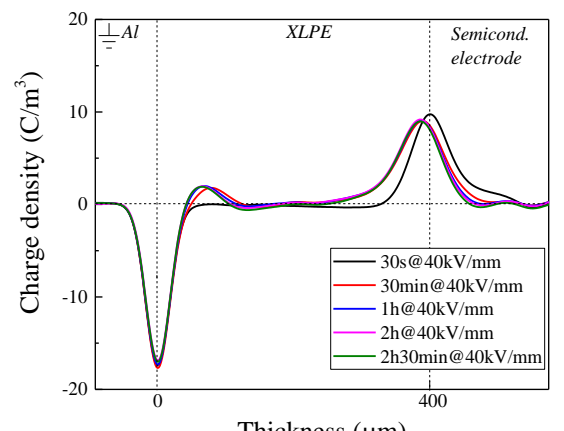

(a) Polarization

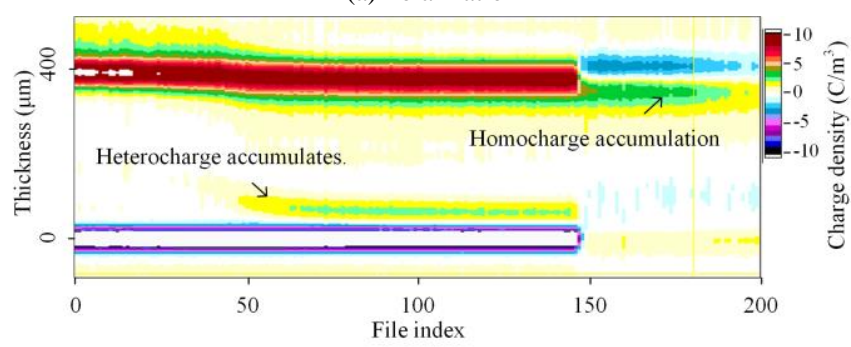

(b) Space charge distribution

Figure 7. Space charge profiles of specimen $\mathrm{C}$ at $40 \mathrm{kV} / \mathrm{mm}$. 
Looking at Figure 7b, during depolarization, heterocharge in the vicinity of cathode is dissipated quite fast while the homocharge accumulated near the anode remains for much longer times.

It can be concluded that near the cathode, no injected charge can be seen, and heterocharge migrating from anode accumulates, in which case electric field near anode decreases. During depolarization, injected homocharge can only be seen in the vicinity of anode. Therefore, graphene coating on the surface of XLPE can suppress the homocharge injection and block heterocharge while it is less efficient on the semicon side during poling phase.

\section{CONCLUSIONS}

A thin graphene coating on insulation surface was here introduced with the aim of limiting injection and accumulation of space charge. Space charge distribution of specimens coated with graphene were analyzed through PEA technique. Graphene coating on XLPE can suppress the injection of charge from electrode. Graphene coated on the semicon side can limit the quantity of charges injected from semicon electrode, which results in the accumulation of negative charges in XLPE. However, graphene coating can be easily removed from semicon surface and this can negatively affect space charge accumulation. Further research is therefore necessary to prevent this problem and improve the efficiency of the coating.

\section{ACKNOWLEDGMENT}

The authors would like to thank the generous help of Nexans for preparing XLPE specimens and Nanesa S.r.l. for coating graphene on specimens.

\section{REFERENCES}

[1] G. Mazzanti, G. Chen, J. C. Fothergill, N. Hozumi, J. Li, M. Marzinotto, F. Mauseth, P. Morshuis, C. Reed, A. Tzimas, and K. Wu, "A protocol for space charge measurements in full-size HVDC extruded cables," IEEE Trans. Dielectr. Electr. Insul., vol. 22, no. 1, pp. 21-34, Jan. 2015.

[2] D. Fabiani, G. C. Montanari, C. Laurent, G. Teyssedre, P. H. F. Morshuis, R. Bodega, L. A. Dissado, A. Campus, and U. H. Nilsson, "Polymeric HVDC cable design and space charge accumulation. Part 1: Insulation/Semicon Interface," IEEE Electr. Insul. Mag., vol. 23, no. 6, pp. 11-19, Dec. 2007.

[3] L. Milliere, K. Makasheva, C. Laurent, B. Despax, L. Boudou, and G. Teyssedre, "Silver nanoparticles as a key feature of a plasma polymer composite layer in mitigation of charge injection into polyethylene under dc stress,” J. Phys. D: Appl. Phys., vol. 49, no. 1, pp. 015304, Nov. 2015.

[4] B. X. Du, J. Li, H. Du, and Y. Yin, "Effect of surface fluorination on space charge behavior in multilayered polyimide films," IEEE Trans. Dielectr. Electr. Insul., vol. 21, no. 4, pp. 1817-1823, Aug. 2014.

[5] C. Y. Li, J. Hu, C. J. Lin, and J. L. He, "The control mechanism of surface traps on surface charge behavior in alumina-filled epoxy composites," J. Phys. D Appl. Phys., vol. 49, no. 44, pp. 445304, Oct. 2016.

[6] C. Y. Li, C. J. Lin, G. Chen, Y. P. Tu, Y. Zhou, Q. Li, B. Zhang, and J. L. He, "Field-dependent charging phenomenon of HVDC spacers based on dominant charge behaviors," Appl. Phys. Lett., vol. 114, no. 20, pp. 202904 , May 2019.

[7] S. S Lin, Y. H Lu, J. Xu, S. R. Feng, and J. F. Li, "High performance graphene/semiconductor van der Waals heterostructure optoelectronic devices," Nano Energy, vol. 40, no. 10, pp. 122-148, Oct. 2017. 